\title{
Critical Thinking as Disciplinary Practice
}

Stephen C. Yanchar

Brigham Young University - Provo, stephen_yanchar@byu.edu

Brent D. Slife

Brigham Young University - Provo

Russell Warne

Brigham Young University - Provo

Follow this and additional works at: https://scholarsarchive.byu.edu/facpub

Part of the Educational Psychology Commons, and the Educational Technology Commons

\section{Original Publication Citation}

Yanchar SC, Slife BD, Warne R. Critical Thinking as Disciplinary Practice. Review of General Psychology. 2008;12(3):265-281. doi:10.1037/1089-2680.12.3.265

\section{BYU ScholarsArchive Citation}

Yanchar, Stephen C.; Slife, Brent D.; and Warne, Russell, "Critical Thinking as Disciplinary Practice" (2008). Faculty Publications. 5383.

https://scholarsarchive.byu.edu/facpub/5383

This Peer-Reviewed Article is brought to you for free and open access by BYU ScholarsArchive. It has been accepted for inclusion in Faculty Publications by an authorized administrator of BYU ScholarsArchive. For more information, please contact ellen_amatangelo@byu.edu. 
Critical Thinking as Disciplinary Practice 1

Running head: CRITICAL THINKING

Critical Thinking as Disciplinary Practice

Stephen C. Yanchar, Brent D. Slife, and Russell Warne

Brigham Young University 


\begin{abstract}
Critical thinking in psychology has traditionally focused on method-centered tasks such as the assessment of method use, data analysis, and research evidence. Although helpful in some ways, this form of critical thinking fails to provide resources for critically examining the scientific-analytic foundation on which it rests and, when used exclusively, prohibits sufficiently critical analysis of theory and research. An alternative view of critical thinking - that emphasizes the identification and evaluation of implicit theoretical assumptions - is advocated. It is suggested that this alternative approach improves upon method-centered approaches by addressing not only implicit assumptions but also rule-following concerns. This approach is intended to facilitate innovation and the production of scholarly work, in ways that incorporate relational values such as dialogue, care, and respect. Finally, this alternative form of critical thinking is described as a theoretically-situated, open, and evolving conception of critique that should itself be continually re-analyzed and refined, particularly in response to the evolving nature and needs of the field.
\end{abstract}

Key Words: critical thinking, assumptions, implications 


\section{Critical Thinking as Disciplinary Practice}

The prominence of critical thinking in psychology, from college curricula and pedagogy to basic and applied research, is difficult to overestimate. Few observers could seriously question the field's commitment to the assiduous use of logical and methodological rules in the evaluation of evidence, arguments, and knowledge claims. Notwithstanding this considerable emphasis already placed on critical thinking, and while recognizing important advances made with regard to this significant aspect of scholarship in psychology (e.g., Baron \& Sternberg, 1987; Bensley, 1998; Halonen, 1995; Halpern, 2003; Halpern \& Nummedal, 1995; Shiraev \& Levy, 2004), we will recommend a direction for further advancement in the ways critical thinking is conceptualized and implemented. In presenting our position, we will review forms of critical thinking commonly endorsed in the mainstream literature, discuss their strengths and limitations, and explain why the conception we advocate- - which emphasizes the analysis of implicit theoretical assumptions from a relational standpoint—provides more adequate resources for the development of psychological theory and research.

We wish to state at the outset, however, that we do not presume to occupy an impartial or neutral standpoint on the nature and practice of critical thinking. Our position is informed by a set of ideas that, although persuasive in our view, is historically and philosophically situated within a broader intellectual tradition that explicitly recognizes knowing as perspectival, relational, and interpretive. As thinkers such as Heidegger (1962), Gadamer (1975/1989), Bernstein (1983) and others (e.g., Danziger, 1985; Polkinghorne, 2000; Richardson, Fowers, \& Guignon, 1999; Slife \& Williams, 1995; Westerman, 2004) have argued, a background of understanding will be presupposed in 
any effort to more adequately and explicitly understand the world and human involvement within it. We thus present our position on critical thinking, which reflects and perpetuates these basic commitments, as an alternative view of disciplinary critique that can produce tangible benefits, and as an invitation to further discussion about how critical thinking in the discipline might be improved.

\section{Critical Thinking in Psychology}

\section{Trends in the Literature}

It can hardly be doubted that critical thinking in psychology comes in many forms and that no single description could capture the variety and nuance with which it is exercised by instructors, researchers, and practitioners. The scholarly literature, for example, includes a variety of critical approaches stemming from positions as diverse as phenomenology (Giorgi, 1970; Valle \& King, 1978), feminism (Gergen \& Davis, 1997; Morawski, 1994), hermeneutics (Faulconer \& Williams, 1985; Richardson, Fowers, \& Guignon, 1999; Westerman, 2004, 2005), critical theory (Fox \& Prilleltensky, 1997), and social contructionism (Bayer \& Shotter, 1998; Gergen, 1994), as well as analyses rooted in the humanities (Allegretti \& Frederick, 1995; Henderson, 1995) or in various religious or spiritual perspectives (Bergin, 1980; Browning \& Cooper, 2004; Slife, Hope, \& Nebeker, 1999). By and large, however, these kinds of critical analyses occur relatively infrequently and have not led to a significant shift in how critical thinking is generally viewed in the field. Indeed, an even casual glance at the mainstream literature suggests that the ethos of critical thinking in psychology cannot be viewed as harmonious with any of these intellectual movements. 
More common views and definitions of critical thinking in psychology (e.g., Benjafield, 1994; Bensley, 1998; Meltzoff, 1998; Ruscio, 2006; Stanovich, 2004) typically privilege the methods, rules, and values of science, particularly those associated with traditional axioms of research (e.g., objectivity, falsifiability, and operationism), valid uses of technical procedures (e.g., various research paradigms, logics, measurement techniques, and statistical analyses), and appropriate conclusions regarding empirical evidence (e.g., not equating correlation and causation). This strong tendency toward method-centered critical thinking — what might be termed "scientific analytic reasoning" (Dick, 1991, p. 84) —is readily discernable in critical thinking primers (e.g., Benjafield, 1994; Marek, Jackson, Griggs, \& Christopher, 1998; Meltzoff, 1998; Ruscio, 2006), in the teaching of psychology literature (e.g., Connor-Greene \& Greene, 2002; Halpern \& Nummedal, 1995; Lawson, 1999; Leshowitz, Eignor Dicerbo, \& Okun, 2002; Varnhagen \& Digdon, 2002; Williams, et al., 2003), in general treatises on undergraduate education and quality thinking in psychology (e.g., Halonen, et al., 2003; Lehman, Lempert, \& Nisbett, 1988; McBurney, 2002; Stanovich, 2004), and in a host of introductory psychology textbooks (for a review, see Griggs, Jackson, Marek, \& Christopher, 1998).

Other sources in the mainstream literature describe critical thinking strategies that combine scientific analytic reasoning with other critical thinking approaches, but never depart substantially from the overriding disciplinary concern of method-centered scholarship. Indeed, the literature contains numerous examples of scientific analytic reasoning mixed with informal and formal logic concerns (e.g., Bell, 2005; Bensley, 1998; Halonen, 1995; Levy, 1997; Schick \& Vaughn, 1995; Tavris, 2001; Zechmeister \& Johnson, 1992), with findings and principles from cognitive research (e.g., Carey, 1986; 
de Sanchez, 1995; Halpern, 2003), and with the identification of unscientific preconceptions about psychological phenomena (Sheldon, 1999; Smith, 2002). These critical thinking approaches may facilitate student training and critique in the profession in some ways, but they do not invite scholars and students to question the methodcentered foundation upon which much critical thinking in the field rests.

This emphasis on method and method-based reasoning should not be surprising. Perhaps the deepest and most abiding value of psychological science has been its commitment to neutrality and the objective description and explanation of psychological reality, thought to be achieved through the use of procedures that are themselves taken to be neutral and objective (Danziger, 1985, 1990; Gergen, 1994; Polkinghorne, 1983, Slife \& Williams, 1995). We are referring here to a model of inquiry concerned fundamentally with the accrual of facts via the methodical application of well-defined rules - that is, via a standard method. Given this disciplinary emphasis on method-centered concerns, it is not surprising that the critical thinking strategy most widely adopted would concentrate on this investigative resource and the skill with which it is deployed. Other critical thinking considerations, such as identification of formal and informal logical fallacies, are also thought to be helpful if used in conjunction with scientific analytic reasoning.

\section{Limitations of Scientific Analytic Reasoning}

Under this view of critical thinking, methodological rules, procedural details, and related issues are of paramount importance; little else is required of the critical thinker if these concerns have been conscientiously addressed. As we will suggest, such checks on rule-following and the application of research methods play an important role within disciplined inquiry, and so may appropriately be a part of critical analysis. What we find 
missing from such a viewpoint, however, is an appreciation of the theoretical and historical positioning of any particular form of critical thinking, scientific analytic reasoning or otherwise. In short, the idea of a positionless critical analysis that impartially assesses evidence, arguments, and knowledge claims has increasingly been rejected on the grounds that such impartiality is not achievable in practice and involves researchers and practitioners in a fundamental misunderstanding about the nature of critical thought (e.g., Alston, 1995; Burbules, 1995; Martin, 1992; McPeck, 1981; Sears \& Parsons, 1991; Thayer-Bacon, 2000) and science in general (Danziger, 1990; Feyerabend, 1975/1993; Hesse, 1980; Polkinghorne, 1983).

Support for the rejection of theory-neutral, value-free critical thinking is provided in the basic insight that any attempt at critical analysis must begin somewhere, based upon a fallible framework of assumptions regarding the nature of criticism, knowledge, reality, disciplined inquiry, rules of evidence, valid argumentation, and related issues. Those assumptions, then, predetermine what will count as genuine knowledge, valid results, and persuasive argumentation. In this sense, it could be said that the general conclusion of any critical analysis will be presupposed by the basic precepts of the critical thinking strategy employed, and that any critical analysis will involve an implicit form of question begging - including our own analysis of critical thinking in psychology (a point we will address in more detail later).

Although scientific analytic reasoning may often be viewed as a neutral or unbiased mechanism for evaluating research and judging knowledge claims, it too is historically and theoretically positioned and thus subject to this limitation. More specifically, scientific analytic reasoning, particularly as operative in psychology, 
presupposes concepts such as objectivism, universalism, empiricism, mechanism, Humean causation, reductionism, and operationism (Danziger, 1985, 1990; Polkinghorne, 1983; Rakover, 1990; Slife, 1998; Slife \& Williams, 1995) and thus commits critical thinkers who use it to an understanding of inquiry and rationality informed by them. Conclusions based on scientific analytic reasoning, then, will be neither neutral nor impartial judgments, but practical extensions of this theoretical view of good research. This is the case, for example, when a study is evaluated according to common scientificanalytic criteria such as researcher detachment and objectivity, valid measurement, acceptable use of operational definitions, adequate control of extraneous variables, appropriate statistical analysis, and the generalizability of results. Research projects judged as faulty in any of these respects are not likely to be viewed as legitimate contributions to the knowledge base; scientific analytic reasoning, as a type of critical thinking, is specifically designed to protect against such deficiencies.

Although the need for general rules designed to assess method use is clear, the exclusive use of such rules to evaluate research informed by the same (or similar) assumptions precludes any critical questioning of that method's assumptive framework and its general mode of operation. For example, there is no non-circular way for methodological rules based on the precepts of traditional quantitative research to critically assess those precepts and the quantitative practices that follow from them (Slife \& Williams, 1995). Moreover, authors who advocate scientific-analytic-based approaches have not discussed means by which the core ideas of scientific analytic reasoning per se might be exposed and scrutinized. 
If disciplinary practices include no way to critically assess the investigative activities and methods per se of traditional quantitative research, then those activities and methods will necessarily be considered unproblematic, perhaps implicitly, no matter how poorly they may fit the general topic of inquiry or research question at hand; only the details of their execution will be questioned, thus creating a type of complicity between critical thinking (qua scientific analytic reasoning) and traditional quantitative research practices that prohibits sufficiently penetrating critical analysis. Under this view of critical thinking, only methods and research endeavors that fit within the scope of scientific analytic reasoning will be viewed as capable of producing viable knowledge and thus appropriate for psychological investigation. This historical bias has given rise to a type of methodological orthodoxy that, as critics have argued (Danziger, 1990; Giorgi, 1970; Koch, 1999; Polkinghorne, 1983; Robinson, 2000; Yanchar, Gantt, \& Clay, 2005), forestalls flexible, innovative, and inclusive research by limiting inquirers to only certain kinds of research questions (i.e., those that can be answered by the privileged methods) and devaluing or marginalizing alternative investigative approaches.

It is also important to note that the assumptions of scientific analytic reasoning have not been universally endorsed in the field. Indeed, an increasing number of critics have argued — albeit outside of the disciplinary mainstream - that such assumptions cannot provide sufficient resources for a science that must deal with the complexities of human life situated in richly meaningful and value-laden contexts (e.g., Danziger, 1985, 1990; Gergen, 1994; Leaf, 1993; Martin, Sugarman, \& Thompson, 2003; Polkinghorne, 1983; Richardson, Fowers, \& Guignon, 1999; Slife \& Williams, 1995; Yanchar, Gantt, \& Clay, 2005). As others have argued, various qualitative alternatives, although not 
harmonious with many of the canons of scientific analytic reasoning, provide useful investigative resources in this regard and should be evaluated according to appropriate standards of quality (Guba, 1981; Merrick, 1999; Morrow, 2005; Stiles, 1993). Thus, although scientific analytic reasoning can be usefully applied in some circumstances, it cannot be assumed to provide adequate critical resources for all human science endeavors.

Viewed in this light, scientific analytic reasoning could hardly be considered a neutral or objective undertaking that protects against threats to the production of veridical knowledge. Indeed, from this perspective, scientific analytic reasoning, as a way of thinking critically about scholarly work, constitutes a theory regarding valid evidence, arguments, and knowledge claims, and thus provides conceptual limits on the kinds of critical examinations and evaluations that can be offered. We hasten to add that this point applies to other critical thinking strategies as much as it does to scientific analytic reasoning. That is, any critical thinking strategy will be based on some values and prior conceptions regarding what will count as valid research or argumentation (Hostetler, 1994; Martin, 1992) that, in turn, obviate the possibility of purely neutral and atheoretical critical assessments. Understood this way, any critical thinking strategy will be, at bottom, a theory of critique.

However, our conclusion in this regard does not necessarily negate the usefulness or applicability of any particular form of critical thinking, or of critical thinking per se. As others have argued, the theoretical background of any method, tool, or procedure is what makes it useful for a particular application in the first place (Bohman, 1991; Gadamer, 1975/1989; Hook, 1996/1927). One theorist used the phrase "enabling 
condition" (Bohman, 1991, p. 125) to describe the theoretical background that makes any understanding, including disciplined inquiry or critical thinking, possible. Although enabling conditions rule out the possibility of neutral, unbiased inquiry, they provide an essential starting point that will guide critical analysis and permit one to produce judgments of one type or another. This central point about critical thinking suggests that any form of critique, as a theory about evidence and argumentation, will be perspectival and so must be used reflectively, cautiously, and with an awareness of its impact on scholarship overall. Our corollary claim, based on our review of the critical thinking literature in psychology and on disciplinary practices in general, is that scientific analytic reasoning has not typically been treated in this manner. In this sense, we do not oppose such reasoning per se; rather, we oppose a particular understanding of its use as a neutral and perspective-free tool of inquiry. Not only is this understanding false, in our view, but it also prevents any critical evaluation of this form of reasoning.

\section{Concerns from Other Fields}

The perspectival nature of criticism has not gone unnoticed in fields outside of psychology, such as philosophy and education, that have traditionally pioneered work in the area of critical thinking. For many in these fields, the lack of impartial critique suggests that critical thinking should not be exercised as if it were a purely objective and mechanical exercise - that is, as if critics were progressively stripping away falsity and error by virtue of algorithmic, context-free rules of rationality. Rather, for these scholars, critical thinking occurs in an indelibly human context that entails considerations not typically addressed in the critical thinking literature of psychology. While we do not expect that psychologists will model their work in every respect after scholarship in these 
other fields, we will discuss two primary considerations that, as scholars in these fields have suggested, are important aspects of adequate critical thinking practice.

The first consideration has to do with the importance of relationships to critical thinking. As some have argued (e.g., Gergen, 1994; Richardson, Fowers, \& Guignon, 1999; Slife, 2005), a relational atmosphere that allows for productive dialogueincluding the open and nondefensive exchange of ideas - can best facilitate the fair consideration of one another's viewpoint and contributions. Critical thinking, in this sense, necessitates the process of reading (or listening) and interpreting in an effort to genuinely understand an author's intention prior to the rendering of critical assessments. Commentators outside of psychology have taken this notion a step further, arguing that critical thinking should entail forms of care and respect that are not typically associated with criticism in the modern tradition that gave rise to scientific analytic reasoning (Martin, 1992; Norris, 1995; Thayer-Bacon, 2000). In the context of critical thinking, care and respect involve characteristics such as attentiveness, empathy, compassion, receptivity to alternative views, and perhaps even sympathy in the course of critical examination. According to these theorists, care and respect are essential—perhaps just as essential as reason itself - if a critical thinker is to fairly consider the work and ideas of others and offer constructive criticism.

The second consideration has to do with the possibility of critical thought that serves a productive function, involving creativity and imagination that facilitate the development of new perspectives and practices. If, as some have argued, creative powers must be exercised in the crucial scientific work of developing and revising theories and conducting progressive research (Feyerabend, 1975/1993; Holton, 1973; McPeck, 1981; 
Nickles, 1980; Robinson, 2000; Sternberg, 1996; Yanchar, Gantt, \& Clay, 2005), then a form of critical thinking that facilitates the work of creativity and innovation would be of great value. Scientific analytic reasoning can facilitate this productive function in some ways - for instance, in helping researchers design the soundest research possible within accepted guidelines - but it cannot cultivate the development of ideas that diverge from those guidelines because it is itself guided by them. In this sense, it might be said that scientific reasoning facilitates work within the context of justification, where ideas are formally tested according to certain protocol, but offers little if any support to the innovation and cultivation of ideas within the context of discovery (see McPeck, 1981, for more on this argument).

Toward An Alternative Conception of Critical Thinking Our Basic Contentions Regarding Critical Thinking

We recognize the challenges involved in proposing a new emphasis for critical thinking in the field, as well as the considerable variation found in definitions and practices within and across scholarly disciplines (Beyer, 1987; Halonen, 1995; Johnson, 1992; Thayer-Bacon, 2000). Indeed, the long history of debate surrounding the meaning of critical thinking (see Thayer-Bacon, 2000) suggests that no approach is likely to be universally accepted or to provide sufficient resources for critical analysis across all fields and under all circumstances. Still, scholars can attempt to approach a broader and more balanced approach to critical thinking in psychology than has been commonly accepted. Our attempt to do so focuses on the importance and consequences of assumptions in a real-world sense and holds that such considerations should take precedence over the details of method use and related activities. While the alternative we 
describe is concerned primarily with how ideas and values inform human life, science, and society at multiple levels, the method-centered approach of mainstream psychology emphasizes procedural details and abstract problems (such as testing the validity of logic) that are of little value if the ideas that guide one's work are in some sense problematic.

From our relational perspective, a more useful form of critical thinking can be defined as the identification and evaluation of ideas, particularly implicit assumptions and values, that guide the thinking, decisions, and practices of oneself and others. This approach to critical thinking principally involves the evaluation of those assumptions by assessing their implications for human life, social issues, and knowledge producing enterprises such as science and other forms of scholarship. Researchers engaged in the form of critical thinking that we recommend, then, would seek to understand as thoroughly as possible the assumptions that inform their theories and methods, and, moreover, those that inform alternatives. Such understanding can facilitate a type of comparison and contrast that clarifies the meaning of theories and methods and leaves researchers in a better position to adopt those most suitable for their purposes.

On the other hand, research that is produced without an awareness of the ideas by which it is guided, and thus the ideas that it implicitly perpetuates, can only be viewed as uninformed (Burgess-Limerick, Abernathy, \& Limerick, 1994; Slife, 1998; Slife \& Williams, 1995). Moreover, research programs produced under these circumstances could, quite possibly, be incoherent in that they may either bring together inconsistent ideas that lead to compromised results (see Yanchar \& Williams, 2006, for more on compromised results due to incoherent assumptions and methods), or be theoretically naive, in that they would entail conceptions and practices that succumb to critical scrutiny 
relatively easily and thus are not taken seriously by scholars in a given area of inquiry. In any of these cases, it is not at all clear that best investigative practices could include research that is uninformed, incoherent, or theoretically naive.

Our approach to critical thinking is concerned first and foremost with a class of assumptions that can be differentiated from others, most notably prosaic assumptions, which are essentially taken-for-granted expectations about everyday events (e.g., assuming that a meeting will start on time). Although such assumptions are important and should be handled responsibly, we wish to emphasize the importance of theoretical assumptions, such as those that inform the work of psychological science and typically have to do with the nature of reality, human nature, knowledge, method, progress, ethics, and other fundamental concerns. These assumptions (e.g., determinism, empiricism, reductionism, atomism) direct the work of researchers, often implicitly, by providing a conceptual basis for the development of theories and models, the formulation of research questions, the selection and use of methods, and the interpretation of data (BurgessLimerick, Abernathy, \& Limerick, 1994; Hostetler, 1994; Slife \& Williams, 1995). Because such assumptions have important consequences for how research and theorizing are to proceed, they should be of paramount importance to critical thinkers in any field.

The practice of critically examining theoretical assumptions takes on added importance, however, when it is recognized that much of the assumptive basis of theorizing and research in psychology is implicit and thus often unrecognized even by scholars deeply involved in a given area of inquiry (Slife \& Williams, 1995). For example, the theoretical assumption of absolute, linear time, as opposed to the relative or contextual time of contemporary physics, has been shown to have important 
consequences for theorizing and research in psychology (Slife, 1993). Still, it is not typically acknowledged and discussed in the mainstream literature (McGrath \& Tschan, 2004). Without critical analysis that probes into this deeper level of conceptualization, assumptions remain hidden and psychologists promulgate ideas that they are unaware of or have not critically considered. This point about scientific inquiry should alert researchers to the dangers of assuming that methods and results are assumptionless, theory-free, or in some other way neutral. Research methods that may be counterproductive or problematic in some sense will not be recognized as such because they have not been examined with a form of critical thinking designed to inquire into such a possibility.

Although some within the field surely engage in the form of critical thinking we recommend (at least to varying dgrees), it has received strikingly little consideration in the disciplinary literature. For instance, substantive discussion of basic theoretical assumptions in mainstream empirical journal reports occurs only rarely. Similarly, research methods textbooks typically do not provide thorough treatments (e.g., explications and critical examinations) of the main body of assumptions that inform traditional quantitative research procedures, and typically do not contextualize the subject matter to be taught by discussing alternative assumptions and alternative research traditions that may be more applicable for certain questions or classes of phenomena. Given that the critical analysis of theoretical assumptions is often omitted from mainstream psychological discourse, it might also be asked how well this form of critical thinking is conducted by those who are willing to engage in it. It seems reasonable to suppose that scholars in the field will vary in their ability to rigorously explicate and 
evaluate a wide array of theoretical assumptions, and thus it seems reasonable to suggest that continued efforts toward improvement in this critical thinking practice would be beneficial to at least some, if not many. For example, the development of skills that enable researchers to more effectively analyze the assumptions underlying various methods and their method choices would be an important contribution to training and continuing education. However, this sort of training or continuing education would not be pursued unless theoretical assumptions, and a form of critical thinking that emphasizes their importance, are taken seriously at a fairly general level in the discipline.

To address such concerns, we present a conception of critical thinking that is intended to foster a shift away from largely method-centered issues. Our position in this regard is based on scholarly work that views human behavior as contextually-embedded practice and knowledge gathering endeavors as inherently perspectival, relational, interpretive, and unfinalizable. As we stated in our introduction, and as we will clarify in the following sections, this means that our approach to critical thinking (like any other), is historically and theoretically situated and thus not capable of generating impartial judgments regarding scholarly work in the field. Our commitments in this regard follow loosely from the relational tradition of philosophers such as Heidegger (1962), Gadamer (1975/1989), and Bernstein (1983), and are similar in many respects to those of hermeneutically-oriented theorists in psychology such as Faulconer and Williams (1985), Martin and Sugarman (2000), Richardson, Fowers, and Guignon (1999), Polkinghorne (2000), and Westerman (2004, 2005).

In explicating these commitments, however, it is important to note that our shift away from an objectivist view of critical thinking, knowledge, and progress is not 
intended to invoke a type of subjectivism where all claims are arbitrary products of a private consciousness or matters of personal preference. It is our view that that while certainty regarding knowledge and best practices may not be forthcoming through the application of method and logic, historical practices - including those of psychologistsmay be facilitated by exposing what is often left unexamined and often unarticulated to the light of scrutiny and public discussion. As we have suggested, this type of critical examination can place researchers in a more informed position with regard to the ideas and results they promulgate and enable them to more adequately assess those of others.

\section{Components of Critical Thinking Practice}

Following from this view, our conception of critical thinking emphasizes six related components that are characterized principally by their relational nature and by their focus on the explication and evaluation of assumptions and their implications. More specifically, our conception emphasizes: (a) the analysis of implicit theoretical assumptions, (b) dialogue and divergent views, (c) care, (d) the production of scholarly work, (e) appropriate use of rules and logics, and (f) open and evolving critical thinking practices. We will attempt to explicate each of these components in subsequent sections. Although the characteristics we emphasize are theoretically related and fit into a broad and multifaceted view of critical thinking, they should not be construed as forming a rigid logical or chronological sequence that ushers in yet another rule-following strategy. These characteristics, when taken as a whole, enable inquirers to critically examine not only the quality of their technical and investigative practices, but also the tenability of the values and assumptions that give rise to or innovate those practices (including critiques of critical thinking itself, such as our own). On this basis, we suggest that it offers a more 
fully critical conception of critical thinking than what is typically emphasized in the literature of psychology.

Evaluating implicit theoretical assumptions. Although the idea of evaluating implicit theoretical assumptions is not commonly emphasized in the critical thinking and pedagogy literature, and does not typically manifest in reports of empirical work, it has been discussed at length in several sources outside of the disciplinary mainstream (e.g., Burgess-Limerick, Abernathy, \& Limerick, 1994; O’Donahue, 1989; Rakover, 1990; Rychlak, 1988; Slife, Reber, \& Richardson, 2005; Sheldon, 1999; Slife \& Williams, 1995; Yanchar \& Slife, 2004). Moreover, the idea of critically examining formative ideas such as theoretical assumptions to gain a better understanding of their meaning, tenability, and usefulness in practice is prominent in other disciplines such as education (e.g., Brookfield, 1987; Burbules, 1995; Freire, 1970; Hostetler, 1994; Keeley, 1992; McPeck, 1981; Mezirow, 1998) and philosophy (e.g., Burtt, 1954; Ennis, 1982; James, 1907/1978; Paul, 1992; Scriven, 1976). From this critical thinking perspective, there is no neutral position upon which to base one's work and no escape from the need for careful, critical examination of the theoretical background of one's scholarly activities.

The primary task of this form of critical thinking, as we have previously noted, is to analyze the meaning and consequences of theoretical assumptions in the context of human experience and practice, in order to understand what they afford those who would adopt them as a basis for their scholarly and practical activities. Assumptions that appear to offer helpful resources for inquiry and theory construction would provide the most promising basis for continued work in a given area. Although there is no standard method or formula for this kind of analysis, as several critical thinking scholars have argued (e.g., 
Hostetler, 1994; McPeck, 1981), discussions of the dispositions and activities it might generally entail are available (Mezirow, 1998; Slife, Reber, \& Richardson, 2005; Slife \& Williams, 1995; Yanchar \& Slife, 2004). Moreover, specific instances of this form of critical thinking in practice can be found in the literature. To consider just a few examples, Cushman (1990) and Richardson, Fowers, and Guignon (1999) have critically examined the assumption of liberal individualism, casting light on how it influences theories of development, identity, and psychotherapy; Rychlak (1979) and Williams (1992) have critically examined the assumptions of efficient causation and ontological determinism, demonstrating their influence on views of human action and responsibility; Slife (2000) and Wallach and Wallach (1983) have critically examined the notion of hedonism, which has been shown to permeate theories and research in many areas; and Martin, Sugarman, and Thompson (2003) and Robinson (1995) have examined the assumption of reductionism and its effect on psychological science in general. Although critical examinations such as these do not constitute final judgments regarding these formative ideas, they raise insightful questions and challenge scholars in the field to carefully consider (or reconsider) what is often taken for granted.

Research methods have also been subjected to this sort of scrutiny, with inquirers critically analyzing assumptions - including Humean causation (Rakover, 1990; Slife \& Williams, 1995), experimental control (Leaf, 1993), subject-object dualism (BurgessLimerick, Abernathy, \& Limerick, 1994; Westerman, 2005), reductionism and materialism (Slife \& Hopkins, 2005), and objectivism (Danziger, 1990; Gergen, 1994)— that inform commonly used research paradigms such as the experiment and the quasiexperiment. Critical examinations such as these provide insight into theory and inquiry 
that cannot issue from scientific analytic reasoning alone (for reasons we have already stated), and have the potential to facilitate scholarly innovations that would not be possible on the basis of pure rule following.

It is important to note, however, that this form of critical thinking does not stand in opposition to other aspects of inquiry such as formulating models and research questions (and possibly hypotheses), designing and conducting studies, analyzing data, interpreting results, and drawing conclusions. As we view it, the work of identifying and evaluating assumptions should be conducted synchronously with these more commonly acknowledged aspects of scientific work in ways that allow researchers not only to collect data regarding phenomena of interest, but also to consider (and reconsider), as they proceed through the research endeavor, the very ideas that gave rise to those studies and data in the first place. In this sense, thinking critically about assumptions should be considered a normal part of the inquiry process, much like other tasks such as reviewing relevant literature, selecting appropriate research strategies, conducting pilot studies, and critically reflecting on the details of one's research design and procedures in a given situation. It is also important to note that not all assumptions can be known and examined at once and that this critical thinking work must unfold carefully over time. As researchers continue to inquire into a topic - empirically, theoretically, and otherwisethey can heighten their awareness and deepen their understanding of the theoretical assumptions that inform their work. Given the importance of these underlying ideas, we suggest that the identification and evaluation of theoretical assumptions should take on a special priority among the various critical thinking tasks involved in the inquiry process. 
It is also important to note that the outcome of this type of critical analysis is not necessarily the gradual movement toward a monolithic theoretical perspective (or set of assumptions) for psychological work, nor is it the total rejection of one or many extant theoretical perspectives in a given area of inquiry. As we suggested earlier, our critical thinking approach is primarily concerned with offering scholars the resources necessary to evaluate the ideas that inform their theories, methods, and work in general by studying their implications. Such critical thinking is meant to address theories and methods in ways that improve their ability to facilitate progress as adjudged by researchers working within certain traditions or areas of inquiry. Thus, although it is likely that rejection of some or many ideas will occur within specific research programs (because scholars cannot embrace and utilize all ideas and perspectives at once), we do not intend this form of critical analysis to produce a univocal stance on important issues across the field.

Moreover, because the contributions of various ideas, theories, and methods cannot always be known in advance, we do not recommend an approach to critical thinking that obviates from the start certain procedures, inquiry strategies, and theoretical perspectives. Although scholars must take some stance on their subject matter and its investigation as they proceed through the research endeavor, they can also be sensitive to the potential insights from other research programs informed by alternative assumptions. In some cases, researchers may understand insights produced by others in their own unique ways and theoretically reconstrue them to fit their own assumptions (e.g., Westerman's, 2006, reinterpretation of quantitative methods); or indeed, such insights may invite some researchers to critically revisit their own unexamined assumptions. 
The role of dialogue and divergent views. It is not always the case, however, that theoretical assumptions are readily discernable and easily evaluated with regard to their plausibility or usefulness in context. Indeed, although some important theoretical assumptions are fairly obvious and even discussed at times (e.g., textbook discussion of causality, knowledge, and science), others are more subtle and thus are rarely identified or explicitly considered in mainstream discourse (e.g., certain conceptions of time, development, and change; see, for example, Slife, 1993; McGrath \& Tschan, 2004).

For this reason, the evaluation of theoretical assumptions that we have described is best viewed as a relational endeavor, or more specifically, should entail what one critical theorist termed "critical dialogue" (Hostetler, 1994, p. 147; for more on dialogue of this sort, see Bernstein, 1983; Gadamer, 1975/1989; Richardson, Fowers, \& Guignon, 1999; Slife, 2005). This recommendation emphasizes the need to become aware of one's own assumptions and those of others through a type of critical conversation with those whose work represents an alternative perspective and is informed by alternative assumptions. This dialogical activity can be particularly helpful in identifying and evaluating one's own assumptions and values that are not explicitly recognized.

As some have argued (Bernstein, 1983; Hostetler, 1995; Fowers \& Richardson, 1996; Richardson, Fowers, \& Guignon, 1999), those with different perspectives are often able to identify what an individual takes for granted and thus cannot easily discern about his or her own viewpoint and projects. Indeed, by virtue of what may be termed a "clash of divergent views" (Hostetler, 1994, p. 143)—or a form of dialogical comparison and contrast - the meaning and implications of an assumptive framework can become apparent, or at least a little clearer to those who hold it. Given the opacity of many 
theoretical assumptions, we view such dialogue as essential to adequate critical thinking. Moreover, through this dialogical encounter, one can become more aware of another's viewpoint and assumptions, which raises the possibility of attaining new understandings and engaging in new forms of practice that may prove beneficial over time.

Critical thinking and care. The concept of care that we have already noted briefly, and that others have championed, is important to our view of critical thinking in that it should be a primary characteristic of the dialogical relationship through which assumptions and implications are examined and, more generally, should be a motivating factor in critical analyses brought to bear on the work of others. Just as we view critical dialogue and the clash of divergent views as essential to adequate critical analysis, we view care about the potential contributions of others, as well as a disposition toward compassion, sympathy, and respect as necessary to a productive critical dialogue. From our perspective, this type of care should be considered along with other major aspects of critical thinking — such as assumption finding, logical skills, and various dispositionseven if it has received little explicit attention in the critical thinking literature of psychology to this point. Such care can place critical inquirers in a position to engage in genuine dialogue, understand more earnestly the work of others, and be better able to offer appropriate, constructive criticism.

Moreover, care, as we have described it here, can help protect against a one-sided emphasis on questioning, doubting, and judging for the purpose of promoting one's own projects and agenda (Martin, 1992) — what one philosopher referred to as critical thinking in the "weak sense" (Paul, 1992, p. 467). Equally important, in this regard, is a type of humility about one's own position (Westerman, 2004), which increases the likelihood of 
engaging in a genuine dialogue about its strengths and weaknesses in comparison to those of others. Although scholars in the field may or may not revise their prior assumptions as a result of critical dialogical encounters marked by care, respect, and humility, they can better understand the strengths and weaknesses of their own positions and achieve new understandings that broaden their appreciation for others.

Critical thinking as productive. From our perspective, caring dialogical encounters should facilitate critical thinking that aids in the production of scholarly work, not merely by assisting in the identification and understanding of theoretical assumptions, but also by assisting in the development of coherent, practically useful, and theoretically defensible frameworks for inquiry of whatever type. Through sustained dialogue with others who hold varied viewpoints, in conjunction with critical reviews of the literature (including analyses of novel or marginalized ideas), psychologists can formulate the most plausible, defensible, and promising assumptions for their theorizing and research. Thus, the important tasks of situating one's project in the disciplinary literature, providing its rationale, and defending its viability in light of rival possibilities, all require more than cursory attention to the fundamental ideas that guide one's work.

For example, researchers seeking to develop new conceptions of a psychological phenomenon such as learning, or seeking to modify an existing one, would need to demonstrate how their basic tenets are different than, and possibly superior to, current and historical conceptions. To briefly consider one case, such productive critical thought is evident in the work of situated learning (e.g., Bredo, 1994; Lave \& Wenger, 1991), distributed cognition (e.g., Salomon, 1993), and activity theorists (e.g., Engeström, Miettinen, \& Punamäki, 1999) who, in similar ways, have initiated a substantial departure 
from common western views of learning and cognition. These theorists, through their rejection of traditional presuppositions such as the inner-outer epistemological split, the private (self-contained) mind, and organism-environment dualism, were able to develop alternative perspectives that have produced significant innovations in various fields (e.g., Barab, Evans, \& Baek, 2004; Sawchuck, Duarte, \& Elhammoumi, 2006; Wenger, 1998). Although situated learning, distributed cognition and activity theory are not controversyfree or uniformly endorsed movements (e.g., Anderson, Reder, \& Simon, 1996), they demonstrate the importance of clearing a theoretical space and cultivating new lines of theory and research through critical analysis.

Clearly the history of psychology provides evidence of theoretical and methodological innovation over time, but much of this innovation has concentrated on relatively minor variations on general themes, including debates about the best techniques for statistical inference and statistical model building, and the shift from the somewhat mentalistic cognitive psychology of the 1970s and 1980s to the neuroscience-inspired models of contemporary research (both of which assume a type of mechanism and reductionism; for analyses, see Rychlak, 1994; Slife \& Williams, 1995). In these cases, basic assumptions about generalization, quantification, objectivism, mechanism, and reductionism - though foundational to the models and results produced — are not questioned and the depth of critical examination that we recommend is not reached. Examples of fundamental critical analyses are also available in the history of psychology, such as behaviorist treatments of introspection and psychoanalysis and humanist treatments of behaviorism, but critical examinations on this order are relatively rare and still do not focus on many assumptions that have only in the last several decades been 
subject to scrutiny (for examples of such scrutiny, see Bayer \& Shotter, 1998; Bem \& de Jong, 1997; Cushman, 1990; Danziger, 1985, 1990; Gergen \& Davis, 1997; Martin, Sugarman, \& Thompson, 2000; Rakover, 1990; Rychlak, 1988; Slife, Reber, \& Richardson, 2005; Slife \& Williams, 1995).

The role of rule-following approaches. As we have already suggested, our emphasis on theoretical assumptions and values does not preclude the judicious use of various rules and logical systems (e.g., informal logic concerns) in the practice of critically assessing arguments, evidence, and knowledge claims. As important as theoretical assumptions and values are to the work of science, critical analyses must also be concerned with the actual conduct of investigation. If researchers have engaged in traditional quantitative research, for instance, it would seem appropriate and useful to examine their work in terms of the rules and standards that inhere in that type of scholarly activity. In this respect, the field of psychology's traditional emphasis on method use and rule following can facilitate the process of critical analysis.

From our perspective, however, it would also be incumbent upon critical thinkers to carefully consider the assumptions that give rise to the research methods used and studies being examined, including the assumptions that guide the formulation of the research questions themselves, method choices, and data interpretations (Yanchar \& Williams, 2006). Critical analysis at this level can often reveal more about a study and its potential shortcomings or contributions than questions about sample size, statistical analysis, measurement, and experimental or statistical control. It is our position that such method-centered issues, as important as they may be to research, become relevant only after more fundamental decisions about inquiry have been made. 
Moreover, from our perspective, rule-following approaches such as scientific analytic reasoning would need to be critically examined and used flexibly and creatively, with careful attention paid to the context of a research project, so that insightful applications, innovations, or research strategies based on less conventional assumptions would not be not precluded by methodological fiat before their potential usefulness can receive disciplinary consideration. As a substantial body of work in the philosophy of science has suggested, there is no simple and direct relationship between methodological rules and scientific progress (e.g., Feyerabend, 1975/1993; Holton, 1973; Nickles, 1980). Feyerabend's (1975/1993) well-known historical examination of progress in science, for example, provided compelling evidence that important advances often occur despite methodological rules, not because of them. Observers of mainstream research practices in psychology have argued similarly, suggesting that staunch adherence to methodological prescriptions set out in advance has a stifling effect, ushering in theoretical and investigative stagnation (e.g., Danziger, 1990; Koch, 1999; Robinson, 2000; Sternberg, 1996; Stiles, 2006; Yanchar, Gantt, \& Clay, 2005). This is not to say that psychological researchers should overemphasize innovation and produce results so idiosyncratic that they can hardly be evaluated, but that flexible and innovative research practices are, to some important degree, necessary for progressive research.

An open and evolving approach. Critical thinking, as we view, it is not intended to provide a neutral standpoint for critical analysis, but rather a set of priorities that takes as its primary function the explication and evaluation of theoretical assumptions and values. As we have already noted, critical analysis is necessarily perspectival in that any critique will be based on some position regarding the relative worth of various theoretical 
assumptions to be critiqued, and in that sense will have already presupposed something about the topic in question; that is, it will have adopted, implicitly or explicitly, a conceptual stance regarding the target of critical examination. For instance, behaviorists' historical rejection of psychoanalytic theory, based largely on their reading of basic ideas articulated in Freud's writings, were informed by their own assumptions regarding human nature, functioning, mental life, scientific investigation, and related issues. This in itself does not make behaviorist critiques wrong or right, but it shows that their critiques, and indeed, their very interpretations of Freud's writings in the first place, were made possible by prior conceptions - that is, some historically, theoretically informed perspective - about the issues at hand. Stated more simply, these behaviorists critiques were leveled from, and enabled by, a particular position rather than objective conclusions based on brute "facts of the matter."

If critical thinking is inescapably perspectival, as we have contended, then a crucial question concerns the manner in which scholars in the field will frame these perspectival critical analyses. One option, of course, is to proceed as if one's critical thinking strategy is an impartial mechanism for separating truth from falsity, knowledge from mere opinion, and so on, and thus ignore basic issues surrounding the nature and tenability of the critical thinking strategy employed. We would reject this option because it promotes the rather unscientific practice of allowing inquiry to be guided by unacknowledged or unexamined ideas (Slife, 1998; Yanchar \& Williams, 2006) and perpetuates the unhelpful view that impartial critical analysis is possible through the fairly routine steps of a technique or set of rules (for more on this point, see Hostetler, 1994; McPeck, 1981; Walters, 1994). A second option, which we would favor, is to 
develop an awareness of the perspective that enables one's attempts at critical analysis, acknowledge that perspective explicitly in one's work, and submit it to a type of examination that helps guard against insularity and unreflective practice. Thus, from our perspective, although critical thinkers cannot avoid an implicit background of understanding as they engage in the process of critique, they can treat this background responsibly by making it at least somewhat transparent and allowing it to be carefully (re)considered. In this sense, the conceptual background that enables one's critical analyses might be most fruitfully viewed as an open and evolving framework that, although necessary, can be examined and modified over time to render it more suitable for one's general purposes or more able to produce the kinds of critical examinations needed in a given situation.

Again, we offer no impartial method for reflecting critically on the conceptual framework that enables one's analyses of assumptions, but rather a type of dialogical encounter that would provide the occasion for such frameworks to be explicated and examined. More specifically, through critical dialogue and the clash of divergent views that we have already described, scholars can engage in the type of conversation that explores the strengths, weaknesses, and limitations of the various frameworks that would inform their critical analyses. It is possible, from this perspective, that such dialogue would not only enable scholars to become aware of such frameworks, but also to modify or temporarily suspend them as needed under particular circumstances. Indeed, scholars might even come to reject one conceptual framework for another that has attained a type of plausibility and persuasiveness through the dialogical process. 
The open and evolving thrust we have articulated is relevant not only to specific attempts to analyze assumptions, but also to the general critical thinking approach we have advocated here. Although we contend that our general view of critical thinking would be beneficial to the practice of critique and the production of scholarly work in psychology, we are also aware of its historically and theoretically situated nature - that it is not an acontextual or neutral method which guarantees the identification of falsity and error. It is important, in this regard, for our critical thinking approach to entail the recognition that it is itself based on certain theoretical assumptions about science, method, and criticism, and thus, as a theory of critique, invokes a type of circularity like any other form of critical thinking.

As we have already suggested, such circularity, when left unacknowledged and unexamined, creates a problematic situation where the crucial background ideas that guide critical examination per se are never themselves critically examined. Under the open and evolving view of critical thinking that we advocate, on the other hand, critical inquirers would be aware of the guiding assumptions of those inquires and, while acknowledging that they are what make critical thinking of this sort possible, they should not be taken for granted. As a theory of critique - rather than an impartial procedure leading inexorably to certitude - the approach we recommend should not only be used cautiously, flexibly and reflectively, but may also at times be modified to perform certain functions, be suspended in favor of approaches that may be more applicable to particular circumstances, or be used in concert with other critical thinking strategies and scholarly practices that would provide more comprehensive resources overall. 
Furthermore, and perhaps more importantly, we suggest that our approach to critical thinking and its underlying assumptions be continually re-examined and refined (perhaps even radically reconfigured), through critical dialogue, the clash of divergent views, and possibly other activities, to make it progressively more suitable to the evolving state of psychological science in general and to specific situations that require innovative forms of critique. Although there is no known objective standpoint for this work, varied perspectives in dialogue can allow for new understandings and improved forms of practice - including critical thinking practice - to be developed. For instance, a variation on the critical thinking approach that we have advocated might be formulated by scholars who view progress as dependent on method use and who would on that basis modify certain aspects of our position to accommodate this theoretical leaning. In general, critical debate about the assumptions and values underlying our proposal can and should take place; we would welcome such dialogue.

\section{Conclusion}

We are not naïve enough to think that intellectual assent to our thesis will automatically imply a change in disciplinary practice. Habits die hard and entrenched ideologies even harder. Still, we see the beginnings of a ground swell of support for a more relationally-oriented approach to critical thinking (e.g., Brookfield, 1987; Hostetler, 1994; Martin, 1992; Powell, 1992; Sears \& Parsons, 1991; Thayer-Bacon, 2000). Consequently, we do not view our proposal as a formal disciplinary change as much as an important application of ideas that are already fomenting and increasingly gaining traction in several disciplines. We have recommended a conception of critical thinking that, while moving beyond the method-centered approaches common to the literature in 
several ways, still allows for appropriate attention to be paid to method-based concerns. Under this conception, checks on rule following and related tasks are secondary considerations that become relevant only after the implicit theoretical assumptions that guide scientific work have been critically examined (and which must be revisited over time and critically re-examined). Elements of our general approach to critical thinking (e.g., critical dialogue, the clash of divergent views, care and respect) all serve to make this approach more broad and balanced than those typically seen in the literature of psychology - more broad in that it emphasizes a crucial set of critical thinking concerns that are ignored or underemphasized in many other critical thinking strategies, and more balanced in that it provides a framework that allows both rule-following approaches and more basic tasks (such as assumptions analysis) to be used strategically and constructively in the practice of critique. Given the importance of implicit theoretical assumptions to the work of psychologists, this approach would seem to be an essential companion to the traditional tasks of theory construction and data collection. As we have contended, a more fully critical and adequate conception of critical thinking cannot be achieved without it. 


\section{References}

Allegretti, C. L., \& Frederick, J. N. (1995). A model for thinking critically about ethical issues. Teaching of Psychology, 22, 46-48.

Alston, K. (1995). Begging the question: Is critical thinking biased? Educational Theory, $45,225-233$.

Anderson, J. R., Reder, L. M., \& Simon, H. A. (1996). Situated learning and education. Educational Researcher, 2(4), 5-11.

Barab, S. A., Evans, M. A., \& Baek, E-O. (2004). Activity theory as a lens for characterizing the participatory unit. In D. Jonassen (ed.), Handbook of research on educational communications and technology (2 ${ }^{\text {nd }}$ ed., pp. 199-214). Mahwah, NJ: Lawrence Erlbaum Associates.

Baron, J. B., \& Sternberg, R. J. (Eds.) (1987). Teaching thinking skills: Theory and practice. New York: W. H. Freeman and Company

Bayer, B. M., \& Shotter, J. (Eds.) (1998). Reconstructing the psychological subject: Bodies, practices, and technologies. Thousand Oaks, CA: Sage.

Bell, J. (2005). Evaluating psychological information: Sharpening your critical thinking skills ( ${ }^{\text {th }}$ ed.). Boston: Allyn \& Bacon.

Bem, S., \& de Jong, H. L. (1997). Theoretical issues in psychology: An introduction. Thousand Oaks, CA: Sage.

Benjafield, J. G. (1994). Thinking critically about research methods. Needham Heights, MA: Allyn \& Bacon.

Bensley, D. A. (1998). Critical thinking in psychology: A unified skills approach. Pacific Grove, CA: Brooks/Cole. 
Bergin, A. E. (1980). Psychotherapy and religious values. Journal of Consulting and Clinical Psychology, 48, 95-105.

Bernstein, R. J. (1983). Beyond objectivism and relativism: Science, hermeneutics, and praxis. Philadelphia: University of Pennsylvania Press.

Beyer, B. K. (1987). Practical strategies for the teaching of thinking. Boston: Allyn \& Bacon.

Bohman, J. (1991). New philosophy of social science. Cambridge, MA: MIT Press.

Bredo, E. (1994). Reconstructing educational psychology: Situated cognition and Deweyian pragmatism. Educational Psychologist, 29, 23-35.

Brookfield, S. (1987). Developing critical thinkers: Challenging adults to explore alternative ways of thinking. San Francisco: Jossey Bass.

Browning, D. S., \& Cooper, T. D. (2004). Religious thought and the modern psychologies ( $2^{\text {nd }}$ ed.) Minneapolis: Fortress Press.

Burbules, N. C. (1995). Reasonable doubt: Toward a postmodern defense of reason as an educational aim. In W. Kohli (Ed.), Critical conversations in philosophy of education (pp. 82-102). New York: Routledge.

Burgess-Limerick, R., Abernathy, B., \& Limerick, B. (1994). Identification of underlying assumptions is an integral part of research: An example from motor control. Theory and Psychology, 4, 139-146.

Burtt, E. A. (1954). The metaphysical foundations of modern science. Garden City, NY: Doubleday Anchor.

Carey, S. (1986). Cognitive science and science education. American Psychologist, 41, 
1123-1130.

Connor-Greene, P. A., \& Greene, D. J. (2002). Science or snake oil? Teaching critical evaluation of "research" reports on the internet. Teaching of Psychology, 29, 321324.

Cushman, P. (1990). Why the self is empty: Toward a historically situated psychology. American Psychologist, 45, 599-611.

Danziger, K. (1985). The methodological imperative in psychology. Philosophy of the Social Sciences, 15, 1-13.

Danziger, K. (1990). Deconstructing the subject: Historical origins of psychological research. New York: Cambridge University Press.

de Sanchez, M. A. (1995). Using critical-thinking principles as a guide to college-level instruction. Teaching of Psychology, 22, 72-74.

Dick, R. D. (1991). An empirical taxonomy of critical thinking. Journal of Instructional Psychology, 18, 79-92.

Engeström, Y., Miettinen, R., \& Punamäki, R-L. (Eds.) (1999). Perspectives on activity theory: Learning in doing: Social, cognitive, and computational perspectives. New York: Cambridge University Press.

Ennis, R. H. (1982). Identifying implicit assumptions. Synthese, 51, 61-86.

Faulconer, J. E., \& Williams, R. N. (1985). Temporality in human action: An alternative to positivism and historicism. American Psychologist, 40, 1179-1188.

Feyerabend, P. (1993). Against method ( $3^{\text {rd }}$ edition). London: Verso. (original work published 1975)

Fox, D., \& Prilleltensky, I. (1997). Critical psychology: An introduction. Thousand Oaks, 


\section{CA: Sage.}

Fowers, B. J., \& Richardson, F. C. (1996). Why is multiculturalism good? American Psychologist, 51, 609-621.

Freire, P. (1970). Pedagogy of the oppressed. New York: Continuum.

Gadamer, H. G. (1989). Truth and method ( $2^{\text {nd }}$ edition). New York: Continuum. (original work published 1975)

Gergen, K. J. (1994). Realities and relationships: Soundings in social construction. Cambridge, MA: Harvard University Press.

Gergen, M. M., \& Davis, S. N. (1997). Toward a new psychology of gender. New York: Routledge.

Giorgi, A. (1970). Psychology as a human science: A phenomenologically based approach. New York: Harper \& Row.

Griggs, R. A., Jackson, S. L., Marek, P., \& Christopher, A. N. (1998). Critical thinking in introductory psychology texts and supplements. Teaching of Psychology, 25, 254265.

Guba, E. G. (1981). Criteria for assessing the trustworthiness of naturalistic inquiries. Educational Communications and Technology Journal, 29, 75-91.

Halonen, J. S. (1995). Demystifying critical thinking. Teaching of Psychology, 22, 7581.

Halonen, J. S., et al. (2003). A rubric for learning, teaching, and assessing scientific inquiry in psychology. Teaching of Psychology, 30, 196-208.

Halpern, D. F. (2003). Thought and knowledge: An introduction to critical thinking ( $4^{\text {th }}$ ed.). Hillsdale, NJ: Lawrence Erlbaum. 
Halpern, D. F., \& Nummedal, S. G. (Eds.) (1995). Special issue: Psychologists teach critical thinking. Teaching of Psychology, 22.

Heideger, M. (1962). Being and time. New York: Harper \& Row.

Henderson, B. B. (1995). Critical thinking exercises for the history of psychology course. Teaching of Psychology, 22, 60-63.

Hesse, M. (1980). Revolutions and reconstructions in the philosophy of science. Bloomington: Indiana University Press.

Holton, G. (1973). Thematic origins of scientific thought: Kepler to Einstein. Cambridge, MA: Harvard University Press.

Hook, S. (1996). The metaphysics of pragmatism. New York: Prometheus Books. (original work published 1927)

Hostetler, K. (1994). Community and neutrality in critical thought: A nonobjectivist view on the conduct and teaching of critical thinking. In K. S. Walters (Ed.), Rethinking reason: New perspectives in critical thinking (pp. 135-154). Albany: SUNY Press.

James, W. (1978). Pragmatism: A new name for some old ways of thinking. Cambridge, MA: Harvard University Press. (original work published 1907)

Johnson, R. H. (1992). The problem of defining critical thinking. In S. P. Norris (Ed.), The generalizability of critical thinking (pp. 38-53). New York: Teacher's College Press.

Keeley, S. M. (1992). Are college students learning the critical thinking skill of finding assumptions? College Student Journal, 26, 316-322.

Koch, S. (1999). Psychology in human context: Essays in dissidence and reconstruction. Chicago: The University of Chicago Press. 
Lave, J., \& Wenger, E. (1991). Situated learning: Legitimate peripheral participation. New York: Cambridge University Press.

Lawson, T. J. (1999). Assessing psychological critical thinking as a learning outcome for psychology majors. Teaching of Psychology, 26, 207-209.

Leaf, R. C. (1993). Control, volition, and the "experimental method.” New Ideas in Psychology, 11, 3-33.

Lehman, D. R., Lempert, R. O., \& Nisbett, R. E. (1988). The effects of graduate training on reasoning: Formal discipline and thinking about everyday-life events. American Psychologist, 43, 431-442.

Leshowitz, B., Eignor Dicerbo, K., \& Okun, M. A. (2002). Effects of instruction in methodological reasoning on information evaluation. Teaching of Psychology, 29, $5-10$.

Levy, D. A. (1997). Tools of critical thinking: Metathoughts for psychology. Boston: Allyn and Bacon.

Marek, P., Jackson, S. L., Griggs, A. R., \& Christopher, A. N. (1998). Supplementary books on critical thinking. Teaching of Psychology, 25, 266-269.

Martin, J. R. (1992). Critical thinking for a humane world. In S. P. Norris (Ed.), The generalizability of critical thinking (pp. 163-180). New York: Teacher's College Press.

Martin, J., \& Sugarman, J. (2000). Between the modern and the postmodern: The possibility of self and progressive understanding in psychology. American Psychologist, 55, 397-406.

Martin, J., Sugarman, J., \& Thompson, J. (2003). Psychology and the question of agency. 
Albany: SUNY Press.

McBurney, D. H. (2002). How to think like a psychologist: Critical thinking in psychology (2 ${ }^{\text {nd }}$ ed.). Upper Saddle River, NJ: Prentice Hall.

McGrath, J. E., \& Tschan, F. (2004). Temporal matters in social psychology: Examining the role of time in the lives of groups and individuals. Washington DC: American Psychological Association Press.

McPeck, J. E. (1981). Critical thinking and education. New York: St. Martin's Press. Meltzoff, J. (1998). Critical thinking about research: Psychology and related fields. Washington DC: American Psychological Association.

Merrick, E. (1999). An exploration of quality in qualitative research: Are "reliability" and "validity" relevant? In M. Kopala \& L. A. Suzuki (Eds.), Using qualitative methods in psychology (pp. 25-36). Thousand Oaks, CA: Sage Publications.

Mezirow, J. (1998). On critical reflection. Adult Education Quarterly, 48, 185-198.

Morawski, J. G. (1994). Practicing feminisms, reconstructing psychology: Notes on a liminal science. Ann Arbor, MI: University of Michigan Press.

Morrow, S. L. (2005). Quality and trustworthiness in qualitative research in counseling psychology. Journal of Counseling Psychology, 52, 250-260.

Nickles, T. (Ed.) (1980). Scientific discovery: Case studies. Boston: D. Reidel Publishing Company.

Norris, S. P. (1995). Sustaining and responding to charges of bias in critical thinking. Educational Theory, 45, 199-211.

O’Donohue, W. (1989). The (even) bolder model: The clinical psychologist as metaphysician-scientist-practitioner. American Psychologist, 44, 1460-1468. 
Paul, R. (1992). Critical thinking: What every person needs to survive in a rapidly changing world. Sonoma State University: Foundation for Critical Thinking, 1992.

Polkinghorne, D. E. (1983). Methodology for the human sciences: Systems of inquiry. Albany, NY: SUNY Press.

Polkinghorne, D. E. (2000). Psychological inquiry and pragmatic and hermeneutic traditions. Theory \& Psychology, 10, 453-479.

Powell, R. G. (1992). Critical thinking and speech communication: Our teaching strategies are warranted-not! Journal of Applied Communication Research, 20, $342-347$.

Rakover, S. S. (1990). Metapsychology: Missing links in behavior, mind, and science. New York: Paragon House.

Richardson, F. C., Fowers, B. F, \& Guignon, C. (1999). Re-envisioning psychology: Moral dimensions of theory and practice. San Francisco: Jossey-Bass.

Robinson, D. N. (1995). The logic of reductionist models. New Ideas in Psychology, 13, $1-8$

Robinson, D. N. (2000). Paradigms and 'the myth of framework:' How science progresses. Theory and Psychology, 10, 39-47.

Ruscio, J. (2006). Critical thinking in psychology: Separating sense from nonsense $\left(2^{\text {nd }}\right.$ ed.). Belmont, CA: Wadsworth/Thomson.

Rychlak, J. F. (1979). Discovering free will and personal responsibility. New York: Oxford University Press.

Rychlak, J. F. (1988). The psychology of rigorous humanism ( $2^{\text {nd }}$ ed.). New York: 
New York University Press.

Rychlak, J. F. (1994). Logical learning theory: A human teleology and its empirical support. Lincoln: University of Nebraska Press.

Salomon, G. (Ed.) (1993). Distributed cognitions: Psychological and educational considerations. New York: Cambridge University Press.

Sawchuck, P. H., Duarte, N., \& Elhammoumi, M. (Eds.) (2006). Critical perspectives on activity: Explorations across education, work, and everyday life. New York: Cambridge University Press.

Schick, T. Jr., \& Vaughn, L. (1995). How to think about weird things: Critical thinking for a new age. Mountain View, CA: Mayfield.

Scriven, M. (1976). Reasoning. New York: McGraw-Hill.

Sears, A., \& Parsons, J. (1991). Towards critical thinking as an ethic. Theory and Research in Social Education, 19, 45-68.

Sheldon, J. P. (1999). A secondary agenda in classroom activities: Having students confront their biases and assumptions. Teaching of Psychology, 26, 209-211.

Shiraev, E., \& Levy, D. (2004). Cross-cultural psychology: Critical thinking and contemporary applications. Boston: Allyn \& Bacon.

Slife, B. D. (1993). Time and psychological explanation. Albany: SUNY Press.

Slife, B. D. (1998). Raising the consciousness of researchers: Hidden assumptions in the behavioral sciences. Adapted Physical Activity Quarterly, 15, 208-221.

Slife, B. D. (2000). A symposium: Hedonism - A hidden unity and problematic of psychology. The General Psychologist, 35.

Slife, B. D. (2005). Testing the limits of Henriques' proposal: Wittgensteinian lessons 
and hermeneutic dialogue. Journal of Clinical Psychology, 61(1), 107-120.

Slife, B. D., Hope, C., \& Nebeker, R. S. (1999). Examining the relationship between religious spirituality and psychological science. Journal of Humanistic Psychology, 39, 51-85.

Slife, B. D., \& Hopkins, R. O. (2005). Alternative assumptions for neuroscience: Formulating a true monism. In B. D. Slife, J. S. Reber, \& F. C. Richardson (Eds.), Critical thinking about psychology: Hidden assumptions and plausible alternatives (pp. 121-147). Washington, DC: APA Books.

Slife, B. D., Reber, J. S., \& Richardson, F. C. (Eds.) (2005). Critical thinking about Psychology: Hidden assumptions and plausible alternatives. Washington, DC: APA Books.

Slife, B. D., \& Williams, R. N. (1995). What's behind the research? Discovering hidden assumptions in the behavioral sciences. Thousand Oaks, CA: Sage Publications.

Smith, R. A. (2002). Challenging your preconceptions: Thinking critically about psychology (2 ${ }^{\text {nd }}$ ed.). Belmont, CA: Wadsworth/Thomson.

Stanovich, K. E. (2004). How to think straight about psychology $\left(7^{\text {th }}\right.$ ed.). Boston: Allyn \& Bacon.

Sternberg, R. J. (1996). Is the system for awarding U.S. government basic research grants scientifically bankrupt? American Psychological Society Observer, September, 9, $11-12$

Stiles, W. B. (1993). Quality control in qualitative research. Clinical Psychology Review, 13, 593-618.

Stiles, W. B. (2006). Numbers can be enriching. New Ideas in Psychology, 24, 252-262. 
Tavris, C. (2001). Psychobabble and biobunk: Using psychology to think critically about issues in the news. Upper Saddle River, NJ: Prentice Hall.

Thayer-Bacon, B. J. (2000). Transforming critical thinking: Thinking constructively. New York: Teacher's College Press.

Valle, R. S., \& King, M. (1978). Existential-phenomenological alternatives for psychology. New York: Oxford University Press.

Varnhagen, C. K., \& Digdon, N. (2002). Helping students read reports of empirical research. Teaching of Psychology, 29, 160-164.

Wallach, M. A., \& Wallach, L. (1983). Psychology's sanction for selfishness: The error of egoism in theory and therapy. San Francisco: W. H. Freeman and Company.

Walters, K. S. (1994). Critical thinking, rationality, and vulcanization of students. In K. S. Walters (Ed.), Re-thinking reason: New perspectives in critical thinking (pp. 61-80). Albany: SUNY Press.

Wenger, E. (1998). Communities of practice: Learning, meaning, and identity. New York: Cambridge University Press.

Westerman, M. A. (2004). Theory and research on practices, Theory and research as practices: Hermeneutics and psychological inquiry. Journal of Theoretical and Philosophical Psychology, 24, 123-156.

Westerman, M. A. (2005). What is interpersonal behavior? A post-Cartesian approach to problematic interpersonal patterns and psychotherapy process. Review of General Psychology, 9, 16-34.

Westerman, M. A. (2006). Quantitative research as an interpretive enterprise: The mostly unacknowledged role of interpretation in research efforts and 
suggestions for explicitly interpretive, quantitative investigations. New Ideas in Psychology, 24, 189-211.

Williams, R. L., Oliver, R., Allin, J. L., Winn, B., \& Booher, C. S. (2003). Psychological critical thinking as a course predictor and outcome variable. Teaching of Psychology, 30, 220-223.

Williams, R. N. (1992). The human context of agency. American Psychologist, 47, 752760.

Yanchar, S. C., Gantt, E. E., \& Clay, S. L. (2005). On the nature of a critical methodology. Theory and Psychology, 15, 27-50.

Yanchar, S. C., \& Slife, B. D. (2004). Teaching critical thinking by examining assumptions. Teaching of Psychology, 31, 85-90.

Yanchar, S. C., \& Williams, D. D. (2006). Reconsidering the compatibility thesis and eclecticism: five proposed guidelines for method use. Educational Researcher, 35 (9), 3-12.

Zechmeister, E. B., \& Johnson, J. E. (1992). Critical thinking: A functional approach. Pacific Grove, CA: Brooks/Cole. 